\title{
Patologia do transplante renal: achados morfológicos principais e como laudar as biópsias
}

\section{Renal transplant pathology: main morphological findings and how to sign out biopsies}

Angelo Sementilli'; Daisa Ribeiro David²; Denise Malheiros²; Iria Visona ${ }^{3}$; Karla Laís Pegas ${ }^{4}$; Marcello Franco5; Maria Fernanda Soares ${ }^{6}$; Maria Isabel Albano Edelweiss'; Maria Lúcia Caldas ; Sérgio Araújo ${ }^{3}$

unitermos
Rejeição aguda
Banff
Nefropatia crônica do
enxerto

\section{resumo}

O transplante renal alcançou expressivos e crescentes índices de sucesso desde sua implantação, constituindo atualmente uma terapia substitutiva de larga escala. É cada vez mais freqüente o encontro de biópsias de enxerto renal na rotina dos laboratórios de patologia, cujos achados são os mais variados. Este artigo resulta da experiência dos membros do Clube do Rim (da Sociedade Brasileira de Patologia) e apresenta um panorama geral da patologia do transplante renal, enfatizando a atual classificação de Banff, com suas principais categorias e entidades de diagnóstico problemático.

\section{abstract}

Renal transplant has reached remarkable and growing rates of success since its introduction; nowadays it is a widely used replacement therapy. Renal allograft biopsies are increasingly more frequent in the routine of pathology laboratories, whose histological findings are varied. This paper results from the expertise of the members of the Kidney Club of Sociedade Brasileira de Patologia, and presents a general overview of renal allograft pathology, focusing on the current Banff classification, its main categories and cases of difficult diagnosis.

\section{key words}

Acute rejection

Banff

Chronic allograft

nephropathy

1. PhD; Universidade Metropolitana de Santos (UNIMES); Centro Universitário Lusíadas (UNILUS).

2. PhD; Universidade de São Paulo (USP).

3. Médicos patologistas do Departamento de Patologia da Universidade Federal de São Paulo (UNIFESP).

4. Médica patologista da Irmandade da Santa Casa de Misericórdia de Porto Alegre.

5. Professor titular do Departamento de Patologia da UNIFESP.

6. Doutoranda do Departamento de Patologia da UNIFESP; bolsista pela Coordenação de Aperfeiçoamento de Pessoal de Nível Superior (CAPES); Salomão \& Zoppi Medicina Diagnóstica.

7. PhD; Departamento de Patologia da Faculdade de Medicina da Universidade Federal do Rio Grande do Sul (UFRCS).

8. PhD; Centro de Ciências Médicas da Faculdade de Medicina da Universidade Federal Fluminense (UFF).

Os autores são membros do Clube do Rim, da Sociedade Brasileira de Patologia (SBP). 


\section{Introdução}

O transplante renal foi introduzido como terapia substitutiva em larga escala a partir da década de 1960, alcançando expressivo crescimento na década de 1980. A introdução de novos agentes imunossupressores, particularmente os inibidores da calcineurina (INC), proporcionou expressiva diminuição da incidência de rejeição aguda (RA), que, dos anteriores 50\%, diminuiu para cerca de 10\% nos últimos 10 anos, com a manutenção desse índice nos últimos quatro a cinco anos.

A RA do enxerto renal é evento comum no pós-transplante recente e tardio, e a biópsia renal é o procedimento padrão-ouro para o diagnóstico das condições que podem afetar o enxerto ${ }^{(3,11,37,49)}$. A RA caracteriza-se por endotelite/ arterite e inflamação tubulointersticial. A adoção da biópsia renal para o diagnóstico e o seguimento dos episódios de rejeição levou à descrição da histopatologia da RA e ao surgimento de diferentes abordagens diagnósticas.

Em 1991 objetividade e consistência consideráveis foram alcançadas com a introdução do esquema classificatório de Banff( ${ }^{(50,51,60-62)}$. Desde então, padrões para o diagnóstico de rejeição vêm sendo estabelecidos e revisitados, limitando a subjetividade e a heterogeneidade diagnósticas. Atualmente, o esquema classificatório mais amplamente difundido é a Classificação Banff de 1997(50), que sofreu importantes modificações em 2007, na $9^{\text {th }}$ Banff Conference in Allograft Pathology ${ }^{(62)}$.

Este artigo resulta da experiência dos membros do Clube do Rim, da Sociedade Brasileira de Patologia (SBP), e apresenta um panorama geral da patologia do transplante renal, com suas principais categorias e entidades de diagnóstico problemático.

\section{Critérios de adequação das biópsias de transplantes renais}

As indicações da biópsia ficam a critério clínico e cabe ao patologista avaliar as alterações histopatológicas, classificar e graduar as lesões. Os critérios de adequação definem a amostra como:

- insatisfatória, se contiver menos de sete glomérulos e nenhuma secção de artéria;

- marginal, se possuir sete glomérulos e uma artéria;

- adequada, quando forem contados 10 ou mais glomérulos e no mínimo duas secções de artérias(50).
Exige-se um mínimo de sete lâminas, com quatro ou mais cortes por lâmina, sendo três lâminas coradas por hematoxilina e eosina (HE) e ácido periódico de Schiff (PAS) ou prata, e uma pelo tricrômico (de Masson ou variantes), cortadas em espessura entre 3 e $4 \mu \mathrm{m}$. Esses cuidados são importantes para se avaliar corretamente a biópsia, tendo em vista que determinadas lesões ocorrem focalmente. São usados, em biópsias de transplantes renais, os critérios quantitativos para as lesões da rejeição( ${ }^{(50,62,65)}$.

Para o estudo por microscopia de imunofluorescência (IF) o número adequado de glomérulos é menor, sendo importante para o diagnóstico diferencial entre glomerulonefrite recidivada ou "de novo" e glomerulopatia do transplante, nos casos crônicos. A pesquisa de anticorpos antiagentes infecciosos, como poliomavírus e citomegalovírus, entre outros, e marcadores diagnósticos de doença linfoproliferativa do transplante pode ser realizada por estudo imuno-histoquímico ou hibridização in situ em material fixado e incluído em parafina.

Para a microscopia eletrônica, com amostras muito menores, os diagnósticos são mais específicos, visando encontrar, entre outros achados, duplicações de alças capilares, membrana basal tubular multiestratificada (multilayering), depósitos eletrondensos e inclusões virais.

\section{Biópsias pré-transplante de rins de cadáver para doação}

Na prática atual da patologia do transplante é cada vez mais comum a seleção de doadores de rim chamados borderline: potenciais doadores que apresentam um ou mais fatores clínicos que podem estar associados a dano estrutural do órgão, como, por exemplo, idade avançada (em geral acima de 60 anos), hipertensão, morte por acidente vascular cerebral (AVC) e alterações laboratoriais da função renal(52).

Embora a biópsia pré-transplante deva ser feita de rotina, nos casos acima descritos ela é imperativa para decidir se o rim é adequado ou não ao transplante, levando-se sempre em consideração as condições e a compatibilidade do receptor. Nesses casos, o patologista é solicitado a avaliar a viabilidade do rim, geralmente em curto espaço de tempo. Para esse fim, dispomos de duas técnicas:

- exame de congelação;

- processamento rápido do material em forno de microondas, inclusão em parafina e coloração pelo método de 
rotina - procedimento mais demorado e que requer um técnico habilitado, o que nem sempre é possível em finais de semana ou feriados.

Para avaliação da viabilidade do rim, é anotada a porcentagem de glomérulos obsolescentes em relação ao número total de glomérulos na biópsia. O ponto de corte é de $20 \%$; se o total obsolescente ultrapassar esse limite, o rim não é aceito para transplante. Alterações como esclerose segmentar, espessamento capilar e exsudação leucocitária devem constar do laudo. O interstício deve ser avaliado para presença de fibrose, atrofia de túbulos e infiltrado linfomononuclear, quantificando-se essas alterações em termos de porcentagem de extensão cortical. As artérias devem ser analisadas para identificação de alterações crônicas, como proliferação intimal, elastose, espessamento da parede e espessamento hialino. A análise criteriosa dos três compartimentos permite uma visão global da adequação do órgão a ser enxertado e também é fator preditivo da evolução pós-transplante.

O laudo pré-transplante deve ser descrito da maneira mais completa possível, oferecendo ferramentas suficientes para a tomada de decisão clínica e/ou justificativa no caso de o órgão ser descartado.

\section{Rejeição mediada por células T}

Os achados característicos e seus critérios diagnósticos quantitativos, conforme a classificação de Banff 97 e modificações de 2007, estão descritos na Tabela 1.

Conforme o esquema classificatório de Banff, as alterações agudas tubulointersticiais são caracterizadas por tubulite e infiltrado mononuclear intersticial, respectivamente representados pelos escores " $\mathrm{t}$ " e " $\mathrm{i}$ ". As alterações vasculares agudas são definidas pela presença de arterite intimal, inflamação transmural ou necrose da parede arterial, alterações expressas pelos escores " $\mathrm{v}$ ". A RA do tipo I (rejeição tubulointersticial) é caracterizada por tubulite (exocitose linfocitária no epitélio tubular) e infiltrado intersticial linfomononuclear; no tipo II (rejeição vascular) observa-se arterite intimal; e no tipo III, arterite transmural ou necrose fibrinóide da média, com permeação de fibrina e proteínas plasmáticas na parede do vaso e necrose de miócitos $^{(7)}$. A presença de lesões vasculares tem valor na predição de perda do enxerto renal tanto precoce quanto tardia, podendo indicar rejeição esteróide-resistente e prognóstico mais reservado dentro de dois anos a partir do transplante $\mathrm{e}^{(21,30,38)}$.
Os tipos I e II de rejeição aguda do enxerto renal são processos mediados por células T, com base em evidências imunofenotípicas, clínicas e experimentais. Em contrapartida, a RA tipo III não é responsiva à terapia anticélulas T e é mediada por anticorpos ${ }^{(32,33)}$. Os anticorpos imunoglobulina da classe M ( $\lg M)$ e imunoglobulinas da classe G (IgG1 e IgG3) ativam a via clássica do sistema complemento, atraindo neutrófilos e levando à formação do complexo de ataque às membranas (C5b-9).

\section{Rejeição mediada por anticorpo}

As novas tecnologias imunológicas, como a citometria de fluxo e a técnica de Luminex, chamaram a atenção para o fato de que cerca de $18 \%$ dos transplantados renais desenvolvem anticorpos antiantígeno leucocitário humano (anti-HLA), em boa parte especificamente contra os antígenos HLA do doador, como antecipado por Terasaki(63). A correlação entre RA de mau prognóstico e o desenvolvimento de anticorpos específicos contra o doador também foi descrita por Halloran et al., que consideram a ativação do sistema complemento e a participação de neutrófilos os mecanismos patogenéticos mais importantes na rejeição mediada por anticorpo ${ }^{(6,23)}$. A identificação histológica da fração C4d do complemento contribuiu, recentemente, para a demonstração da participação de anticorpos fixadores de complemento na agressão ao enxerto ${ }^{(12,32,33)}$. Esses três achados chamaram a atenção para o fato de que uma parcela das RAs difere fisiopatologicamente da RA celular. Dessa forma, o termo RA mediada por anticorpos passou a integrar a classificação das rejeições (Tabela 1) e a se sobressair em uma fase em que as RAs celulares são cada vez menos freqüentes. Esse fenômeno foi também demonstrado em substancial parcela de casos de rejeição crônica/nefropatia crônica do enxerto (NCE) ${ }^{(8,34)}$.

\section{Rejeição aguda mediada por anticorpos}

Histologicamente, a RA mediada por anticorpos apresenta aspectos variados e distintos. Pode variar desde histologia normal com presença de depósitos de C4d, passando por alterações discretas, como necrose tubular aguda isolada, até presença de infiltrado inflamatório com agressão tubular, glomerulite aguda e capilarite peritubular, esta última principalmente à custa de neutrófilos ${ }^{(32,33,62)}$. À luz dos conhecimentos atuais, ignora-se como é a evolução dos casos histologicamente normais, com a presença 
Tabela 1 Categorias diagnósticas: Banff 97/atualização Banff 2007

Categoria

\section{Critérios}

1. Normal

2. Alterações mediadas por anticorpos: DSA positivo + C4d ou histologia compatível

C4d positivo sem alterações histológicas

Rejeição aguda mediada por anticorpos:

I. Alterações similares a necrose tubular aguda com inflamação mínima

II. Inflamação capilar e/ou glomerular e/ou tromboses

III. Arterial (v3)

Rejeição crônica ativa mediada por anticorpos

3. Borderline

t1, 2 ou $3+\mathrm{i} 0$ ou i1/t1 +i1, 2 ou 3

4. Rejeição mediada por células T

Rejeição aguda mediada por células T:

Tipo IA

$\mathrm{t} 2+\mathrm{i} 2$ ou 3

Tipo IB

t3 + i 2 ou 3

Tipo IIA

Qualquer $t / i$; 1

Tipo IIB

Qualquer t/i; v2

Tipo III

Qualquer t/i; v3

Rejeição crônica ativa mediada por células T

5. Fl/AT sem evidências de etiologia específica

6. Outras alterações, não atribuíveis à rejeição

A) Critérios quantitativos de tubulite (t)

to

t1

t2

t3
Sem mononucleares tubulares

Focos com 1-4 mononucleares por seção tubular

Focos com 5-10 mononucleares por seção tubular

Focos com >10 mononucleares por seção tubular

B) Critérios quantitativos de inflamação intersticial (i)

i0

i1

i2

i3
Sem inflamação significante

$10 \%-25 \%$ de inflamação intersticial cortical

26\%-50\% de inflamação intersticial cortical

$>50 \%$ de inflamação intersticial cortical

C) Critérios quantitativos de glomerulites (g)

g0

g1

g2

g3
Sem glomerulites

Glomerulites em até $25 \%$ dos glomérulos

Glomerulites em até 25\%-75\% dos glomérulos

Glomerulites em $>75 \%$ dos glomérulos

DSA: anticorpo específico contra o doador. 
de depósitos de C4d, razão pela qual o encontro de Banff 2007 nomeou essa condição "depósito de C4d sem evidência morfológica de rejeição aguda"(22, 62). Nos casos de rejeição crônica, as alterações podem ser acompanhadas de glomerulopatia crônica do transplante, arteriopatia crônica do enxerto, fibrose intersticial e atrofia tubular. A glomerulopatia crônica do transplante (gt) é entidade histológica caracterizada pela duplicação da membrana basal glomerular à microscopia óptica. Apesar de rara no primeiro ano pós-transplante (freqüência de $4 \%$ ), sua freqüência pode chegar a até $20 \%$ após o quinto ano ${ }^{(10,19,59)}$. Relaciona-se com má evolução do enxerto e com a presença de anticorpo anti-HLA classe I. O diagnóstico diferencial histológico da glomerulopatia do transplante faz-se com outras condições histológicas também caracterizadas por duplicação da membrana basal glomerular como recidiva de glomerulonefrite membranoproliferativa, microangiopatia trombótica e quadros de isquemia.

No encontro de Banff 2007 discutiu-se a padronização da marcação para C4d. Foram criados critérios de:

- quantificação da positividade da biópsia, que é avaliada em cinco campos de grande aumento, tanto em cortical, quanto em medular;

- interpretação de acordo com a técnica empregada ${ }^{(55,62)}$.

Tanto à IF quanto à imunoperoxidase, a marcação de positividade é dada pela marcação linear e confluente do endotélio dos capilares peritubulares. Além disso, discutiu-se também a criação de um sistema de escore para a avaliação da inflamação dos capilares peritubulares.

No momento atual dos transplantes de órgãos sólidos, particularmente para o transplante de rim, é importante salientar que somente a histologia básica utilizada na rotina diária sem o uso das técnicas de imuno-histoquímica (IHC) e/ou biologia molecular pode comprometer o diagnóstico e 0 prognóstico do enxerto, visto que histologias aparentemente "inocentes" podem esconder diagnósticos mais graves.

\section{Histopatologia da nefrotoxicidade dos inibidores da calcineurina nos enxertos renais}

Os INC (ciclosporina e tacrolimo) são imunossupressores efetivos na prevenção da rejeição em transplante renal. O mecanismo de ação dessas drogas está associado à prevenção da ativação de células T, pela inibição da calcineurina, uma fosfatase intracelular, com conseqüente bloqueio da síntese da interleucina-2. Dessa forma, os INC são eficazes na redução de episódios agudos e graves de RA, constituindo a terapia primária em transplante renal(4). Tanto a ciclosporina quanto o tacrolimo produzem, porém, efeitos nefrotóxicos que podem comprometer o enxerto, levando a disfunção renal, hipertensão e hiperlipidemia.

As manifestações de nefrotoxicidade podem ser agudas ou crônicas, funcionais e/ou estruturais. As alterações estruturais incluem diferentes lesões histológicas, e a extensão do comprometimento renal pode não se relacionar com o nível sérico das drogas. Ao mesmo tempo, os dois inibidores produzem lesões idênticas, que ocorrem dentro do primeiro ano de vida do enxerto e que, clinicamente, são difíceis de serem diferenciadas de um episódio de RA. Dessa forma, a biópsia renal tem sido a melhor ferramenta diagnóstica da nefrotoxicidade induzida pelos INC e do diagnóstico diferencial desse processo com as diferentes alterações da rejeição aguda e/ou crônica ${ }^{(29,39)}$.

As alterações estruturais renais causadas pela toxicidade a INC incluem lesões em arteríolas, glomérulos, túbulos e interstício.

\section{Nefrotoxicidade aguda}

\section{Tubulopatia tóxica}

É caracterizada por vacuolização tubular isométrica (pequenos vacúolos citoplasmáticos, preenchendo o citoplasma das células epiteliais tubulares). A lesão predomina na porção reta dos túbulos proximais, podendo também envolver a porção contornada e até o epitélio parietal da cápsula de Bowman. Ultra-estruturalmente, os vacúolos correspondem à dilatação do retículo endoplásmico. Não há correlação entre o grau de vacuolização e os níveis sanguíneos dos INC. A lesão pode ser reversível com a redução da dosagem das drogas. O diagnóstico diferencial inclui a nefrotoxicidade por contraste radiológico e a nefrose osmótica.

\section{Toxicidade vascular}

A toxicidade direta ao endotélio pode ou não estar associada à agregação plaquetária. São dois os tipos de lesão vascular:

- arteriolopatia aguda - os pacientes apresentam disfunção aguda do enxerto e as alterações são evidentes nas arteríolas aferentes e porções terminais das artérias interlobulares. Há 
edema e vacuolização das células endoteliais, com necrose e/ ou apoptose, associados à necrose focal de miócitos e posterior hialinização. A análise imuno-histoquímica revela acúmulos de $\operatorname{lgG}$ e C3. A necrose focal de miócitos na média das pequenas artérias, na ausência de alterações intimais, é considerado indicador confiável desta toxicidade. Embora arteriolopatia seja lesão pouco comum, é considerada a lesão mais específica da

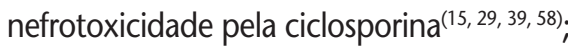

- microangiopatia trombótica (MAT) - essa lesão tóxica vascular assemelha-se clinicamente à síndrome hemolíticourêmica. Na biópsia, as alterações da MAT correspondem a trombos na luz de arteríolas e capilares glomerulares. O diagnóstico diferencial inclui RA mediada por anticorpos, infecções bacterianas e virais, síndrome hemolítico-urêmica recorrente e MAT induzida por anticorpo anticardiolipina. Como a MAT induzida por INC faz parte do diagnóstico diferencial da disfunção aguda do enxerto renal, a indicação precoce da biópsia renal nesses casos resulta na preservação da integridade do enxerto e reduz a morbidade de suas graves complicações ${ }^{(18,26,46)}$.

\section{Nefrotoxicidade crônica}

\section{Arteriolopatia hialina}

As lesões da arteriolopatia hialina desenvolvem-se dentro de poucos dias ou semanas do transplante e progridem em intensidade de $5 \%$ a $9 \%$ em seis meses. A incidência cumulativa da arteriolopatia induzida pelos INC é de 100\% dos casos até 10 anos do transplante. Na progressão para cronicidade, a lesão, inicialmente segmentar, pode ou não envolver toda a circunferência da parede vascular. Nos estágios mais avançados, ocorre espessamento hialino acentuado e conseqüente estreitamento da luz vascular, levando a hipóxia e lesões irreversíveis como glomerulosclerose focal e segmentar, atrofia tubular e fibrose intersticial, com distribuição em faixa ou difusa.

O escore Banff 97 para arteriolopatia hialina associada aos INC tem mostrado índices baixos de reprodutibilidade, sendo necessários novos critérios para avaliação da lesão(15, 58, 62). No Banff 2007 foram propostos critérios mais específicos para a caracterização dessa arteriolopatia, cuja gravidade é quantificada em relação ao envolvimento circunferencial ou não da parede vascular e ao número de arteríolas comprometidas. Esse sistema será avaliado nos próximos dois anos e poderá ser utilizado no lugar do escore Banff 97 (Tabela 2).

\section{Glomérulos}

A glomerulopatia associada aos INC inicia-se por lesão direta das células endoteliais dos capilares glomerulares, resultando em alargamento da lâmina rara interna e formação de nova membrana basal com duplicação da

\section{Tabela 2}

Histopatologia da nefrotoxicidade dos inibidores da calcineurina nos enxertos renais

Critérios quantitativos para espessamento arteriolar hialino ('ah')

\begin{tabular}{|c|c|c|c|}
\hline ah0 & $\begin{array}{l}\text { Espessamento hialino PAS } \\
\text { negativo }\end{array}$ & aah0 & $\begin{array}{l}\text { Ausência de lesões típicas da } \\
\text { arteriolopatia por INC }\end{array}$ \\
\hline ah1 & $\begin{array}{l}\text { Discreto a moderado } \\
\text { espessamento hialino PAS } \\
\text { positivo em pelo menos uma } \\
\text { arteríola }\end{array}$ & aah1 & $\begin{array}{l}\text { Depósitos hialinos em } \\
\text { substituição a necrose de } \\
\text { células da camada média em } \\
\text { uma arteríola e ausência de } \\
\text { envolvimento circunferencial }\end{array}$ \\
\hline ah2 & $\begin{array}{l}\text { Moderado a grave espessamento } \\
\text { hialino PAS positivo em mais de } \\
\text { uma arteríola }\end{array}$ & aah2 & $\begin{array}{l}\text { Mais de uma arteríola com } \\
\text { depósito hialino e ausência de } \\
\text { envolvimento circunferencial }\end{array}$ \\
\hline ah3 & $\begin{array}{l}\text { Espessamento hialino grave PAS } \\
\text { positivo em muitas arteríolas }\end{array}$ & aah3 & $\begin{array}{l}\text { Envolvimento circunferencial } \\
\text { arteriolar independente do } \\
\text { número de arteríolas envolvidas }\end{array}$ \\
\hline
\end{tabular}

Escore para arteriolopatia induzida por INC Banff 97 ('ah'), em comparação com o escore proposto por Mihastch ('aah'), em avaliação nos próximos dois anos, não incorporado ainda à classificação Banff 2007.

Modificado de Solez ${ }^{(62)}$.

Escore da arteriolopatia hialina induzida por INC ('aah') aaho 
membrana basal glomerular (MBG). A duplicação é caracteristicamente focal e segmentar e associa-se à expansão da matriz mesangial(40).

Outra glomerulopatia descrita em associação com os INC é a glomerulosclerose focal e segmentar - variante colapsante (GEFS-VC), descrita em pacientes em uso de ciclosporina. Os pacientes apresentam disfunção do enxerto renal dois a 24 meses após o diagnóstico, com evolução para terapia dialítica ${ }^{(35)}$.

\section{Interstício}

$\mathrm{Na}$ forma crônica da nefrotoxicidade induzida pelos INC, a lesão tubulointersticial é caracterizada por fibrose em faixa, com atrofia tubular associada, mais evidente e precoce nos raios medulares. A lesão com distribuiç̧ão em faixa é característica desse comprometimento crônico, porém não é específica, podendo ocorrer também na lesão renal hipertensiva.

\section{Biópsias protocolares de rins transplantados com função estável}

Apesar do decréscimo na incidência da RA observada no primeiro ano pós-transplante, a disfunção crônica permanece um problema importante, causada pela NCE.

O valor das biópsias protocolares no seguimento de transplantados ainda não está bem definido. A principal função seria detectar rejeições subclínicas, definidas como sinais histológicos de rejeição celular borderline ou aguda, sem concomitante alteração da função renal| ${ }^{(9,28)}$. O critério utilizado como transplante estável foi de aumento inferior a $10 \%$ no valor da creatinina sérica. Uma segunda função das biópsias protocolares seria a análise das alterações histológicas, através do índice semiquantitativo de lesões crônicas no enxerto (chronic allograft damage index [CADI]) como de forte valor preditivo na evolução do enxerto, antes dos sinais clínicos de deterioração da função renal|(27,53,54,67). São seis os parâmetros histológicos utilizados nos índices:

- inflamação intersticial;

- atrofia tubular;

- fibrose intersticial;

- espessamento fibrointimal arterial;

- aumento da matriz mesangial glomerular;

- porcentagem dos glomérulos globalmente esclerosados.
Os escores utilizados em CADI e Banff 97 vão de 0 a 3, e a soma total poderá ser comparada entre as biópsias de três e 12 meses, ou mesmo com a biópsia inicial do doador. Como a porcentagem de glomérulos esclerosados não faz parte da classificação Banff 97, seguiu-se o seguinte critério como escore:

- 0: sem glomérulo globalmente esclerosado;

- $1:<15 \%$;

- 2: $16 \%$ a $50 \%$;

- 3: > 50\% dos glomérulos esclerosados.

A incidência de rejeição subclínica em transplante renal estável é variável nas diversas populações analisadas, provavelmente devido ao tempo em que foram realizadas as biópsias, além de outros fatores como imunossupressão, estado do doador, compatibilidade do HLA, entre outros ${ }^{(28,37,51)}$.

Da mesma forma ainda não há consenso a respeito do tempo ótimo de realização das biópsias protocolares ${ }^{(41-44)}$. Há relatos de incidência superior a $60 \%$ em um mês, $45 \%$ em três e seis meses e $25 \%$ em 12 meses, incluindo tanto os casos borderline como as RAs grau IA ${ }^{(31)}$. Um dos estudos demonstrou que não há valor preditivo das biópsias de três meses em relação às de longo prazo. As biópsias de seis e 12 meses pós-transplante revelaram maior valor na avaliação do transplante a longo prazo. Outro estudo, realizado com biópsias protocolares um mês pós-transplante, demonstrou que a taxa de sobrevida do enxerto no grupo borderline foi significativamente menor quando comparado com o grupo normal, sugerindo ter utilidade para a avaliação da sobrevida do transplante renal. Os resultados revelaram: 76,2\% de casos sem alterações histológicas significativas, 16,3\% de casos considerados borderline e 7,5\% de casos rotulados como rejeição subclínica. A comparação entre os três grupos revelou perda significativa dos enxertos borderline em cinco anos, quando comparados com o grupo normal. Entretanto, a taxa de perda dos enxertos no grupo com rejeição subclínica não foi significativamente diferente daquela nos casos normais. É provável que o grupo borderline necessite de tratamento anti-rejeição mais prolongado.

\section{Infecções no enxerto renal}

\section{Pielonefrite aguda em transplante}

A pielonefrite aguda é definida como a associação de febre a um ou mais dos seguintes sintomas clínicos ou anormalidades biológicas: dor no enxerto, calafrios, cistite, disú- 
ria, leucocitúria, piúria, bacteriúria e aumento da creatinina sérica ${ }^{(1,2)}$. É a terceira causa de disfunção do enxerto, após RA e nefrotoxicidade por inibidor de calcineurina $(\mathrm{ICN})^{(16)}$. Tendo em vista que a pielonefrite pode-se apresentar como insuficiência renal aguda, deve-se considerá-la no diagnóstico diferencial da $R A^{(47,48)}$. Alguns autores consideram a pielonefrite aguda causa potencial de RA em transplante renal, pois a infecção bacteriana ativa o sistema imune, levando potencialmente à rejeição aguda ou crônica ${ }^{(17)}$. Essa hipótese não é apoiada por outros trabalhos que não observaram associação de pielonefrite aguda a incidência aumentada de rejeição aguda ou crônica.

A ocorrência de infecção do trato urinário após o transplante é relativamente comum, chegando a $75 \%$ em algumas séries, principalmente durante o primeiro ano. As bactérias mais envolvidas são: Escherichia coli (80\%), Pseudomonas aeruginosa, Enterococcus sp., entre outras ${ }^{(17,64,66)}$. Outras infecções têm sido descritas, como abscessos perinéfricos por bactérias anaeróbicas, pielite com uropatia obstrutiva por Corynebacterium urealyticum, nefrite bacteriana focal aguda apresentada radiologicamente como massa renal, pielonefrite por Cryptococcus neoformans ${ }^{(25)}$, citomegalovírus, Mycobacterium tuberculosis e fungos, como Candida albicans. A presença de refluxo vesicoureteral é fator de risco significante em rins nativos, uma vez que, em pacientes pediátricos, a pielonefrite aguda é mais freqüente nos transplantados por refluxo vesicoureteral ${ }^{(5)}$. Também pacientes que apresentam rim terminal por pielonefrite têm maior risco de recorrência da doença pós-transplante.

Histologicamente, observa-se processo inflamatório intersticial multifocal com predomínio de neutrófilos, além de cilindros leucocitários, permeação das células tubulares por neutrófilos e edema intersticial. O diagnóstico diferencial com RA é importante, pois na rejeição há tubulite e o infiltrado é predominantemente mononuclear, além de não serem observados cilindros leucocitários neutrofílicos. A necrose tubular aguda é outro diagnóstico diferencial, em que predominam as alterações degenerativo-necróticas e regenerativas epiteliais tubulares e em que o interstício, apesar de se apresentar também edematoso, não apresenta infiltrado inflamatório agudo tão exuberante e cilindros leucocitários neutrofílicos.

\section{Poliomavírus no transplante renal}

Os vírus estão entre as causas mais importantes de infecção oportunista. Estudos moleculares mostram que o poliomavírus do tipo BK (Polyomavirus hominis tipo I) é o que afeta a maioria dos enxertos renais, com prevalência de $1 \%$ a $10 \%$.

Nos pacientes transplantados renais saudáveis, pode-se encontrar poliomavírus na urina, em porcentagem de até $20 \%$ dos casos, enquanto essa incidência cai para menos de 10\% em outros enxertos (coração, pâncreas) e para valores inferiores a 3\% na população geral (em especial gestantes ou diabéticos), mostrando tratar-se de reativação transitória e assintomática de infecção primária ocorrida na infância ${ }^{(13,57)}$.

A maioria dos casos de infecção pelo poliomavírus ocorre no primeiro ano pós-transplante e está confinada ao trato urinário. $\mathrm{O}$ vírus tem tropismo pelos epitélios transicional, tubular e parietal da cápsula de Bowman, aparecendo como inclusões intranucleares nessas células epiteliais. $\mathrm{O}$ diagnóstico correto da nefrite por poliomavírus pode ser feito pelo uso combinado de citologia urinária, biópsia renal e quantificação, por reação em cadeia da polimerase (PCR), da carga viral sanguínea e urinária(13).

O exame citológico urinário é excelente método de triagem para detecção e acompanhamento da infecção, tendo sensibilidade de $100 \%$. As células infectadas são chamadas decoy-cells. Dependendo do estado de replicação e maturação viral e do grau de preservação da célula infectada, são descritos quatro fenótipos para essas alterações citopáticas nucleares:

- clássico: mais comum, com aspecto em "vidro-fosco";

- aspecto eosinofílico com halo claro (diferencial com citomegalovírus);

- aspecto finamente granular difuso;

- núcleos volumosos, com cromatina grosseira (diferencial com células malignas ou em regeneração).

Na biópsia renal, as alterações citopáticas virais podem ser vistas inicialmente em apenas alguns néfrons e ser mais numerosas nos segmentos distais e em ductos coletores da medula. A disfunção renal é causada por necrose tubular e variados graus de inflamação intersticial. O infiltrado inflamatório é linfomononuclear, por vezes contendo plasmócitos e neutrófilos. Há três padrões histológicos observados, relacionados com a gravidade da infecção e a evolução para a perda do enxerto (Tabela 3).

A presença de infiltrado inflamatório e tubulites na nefropatia pelo poliomavírus representa uma dificuldade para o patologista no diferencial entre resposta imunológica à infecção e RA concomitante. Em bases puramente morfológicas, pode ser impossível essa distinção, pois as tubulites ocorrem em ambos os processos. Apenas quando há sinais indubitáveis, como endarterite, glomerulite e necrose fibri- 


\begin{tabular}{|c|c|c|c|}
\hline \multicolumn{2}{|c|}{ Tabela 3} & \multicolumn{2}{|c|}{$\begin{array}{l}\text { Padrões da nefrite tubulointersticial } \\
\text { por polioma }\end{array}$} \\
\hline Padrão & & Histologia & Gradação \\
\hline$A \quad A$ & Alteraçõe & s citopáticas virais & \\
\hline $\begin{array}{ll} & \\
i \\
i\end{array}$ & $\begin{array}{l}\text { Alteraçõ } \\
\text { Variados } \\
\text { inflamaç } \\
\text { interstic }\end{array}$ & $\begin{array}{l}\text { citopáticas virais } \\
\text { graus de } \\
\text { ão, fibrose } \\
\text { al e atrofia tubular }\end{array}$ & $\begin{array}{l}\text { B1: até } 25 \% \\
\text { B2: de } 26 \% \text { a } 50 \% \\
\text { B3: mais de } 51 \%\end{array}$ \\
\hline $\begin{array}{l}\mathrm{F} \\
\mathrm{c} \\
\mathrm{c} \\
\mathrm{i} \\
\mathrm{c} \\
\mathrm{t}\end{array}$ & $\begin{array}{l}\text { Raras alt } \\
\text { citopátic } \\
\text { Graves a } \\
\text { inflamat } \\
\text { de croni } \\
\text { tubuloin }\end{array}$ & $\begin{array}{l}\text { erações } \\
\text { as virais } \\
\text { terações } \\
\text { rias e } \\
\text { idade } \\
\text { ersticiais }\end{array}$ & \\
\hline
\end{tabular}

nóide vascular, é que se pode firmar o diagnóstico de RA concomitante. Merecem também menção como diferenciais o adenovírus, de infecção mais rara e que usualmente cursa com necrose tubular mais grave; e o citomegalovírus, com que o poliomavírus pode ser confundido quando as células infectadas são maiores e com halo perinuclear.

A confirmação definitiva pode ser feita por IHC, em geral utilizando o anticorpo policlonal anti-SV-40. Também pode ser realizada hibridização in situ ou PCR, para a detecção do genoma viral. O diagnóstico por PCR na quantificação da carga viral na urina (virúria) ou no sangue (viremia) tem demonstrado forte relação com o grau de acometimento renal. Por fim, a microscopia eletrônica pode também confirmar a presença do vírus, com base na morfologia ultra-estrutural característica.

\section{Avanços no Banff}

Desde a introdução da classificação de Banff para as biópsias renais, as categorias diagnósticas vêm sendo constantemente alteradas ${ }^{(50,51,60-62)}$. Na última conferência do Banff, em 2007, as principais alterações introduzidas foram a incorporação da entidade "rejeição humoral crônica", o uso da terminologia "rejeição mediada por células T" e a recomendação de não-utilização do termo "nefropatia crônica do transplante", de modo que as categorias diagnósticas propostas, além da normalidade, são basicamente cinco:

- rejeição mediada por anticorpos;

- alterações borderline;

- rejeição mediada por células T;
- fibrose intersticial e atrofia tubular, sem evidências de etiologia específica;

- outros (hipertensão, toxicidade a drogas, obstrução crônica, pielonefrite bacteriana, infecção viral).

\section{Rejeição mediada por anticorpos}

É caracterizada pela presença de: anticorpos anti-HLA do doador (padrão-ouro - parâmetro fundamental); depósitos de $\mathrm{C} 4 \mathrm{~d}$ em capilares peritubulares; e alterações à microscopia óptica (necrose tubular aguda ou glomerulite neutrofílica, microangiopatia trombótica, capilarite peritubular ou necrose fibrinóide arterial/inflamação transmural arterial).

A comparação entre IF e IHC para a detecção de C4d favoreceu a IF, por ser mais reproduzível entre os patologistas ${ }^{(55)}$. No consenso Banff 2007, a positividade do C4d deve ser expressa em graus. Deve-se lembrar que o C4d é comumente positivo no mesângio glomerular e em rins nativos com glomerulonefrite membranosa e nefrite lúpica.

Os critérios histológicos de rejeição crônica mediada por anticorpos baseiam-se morfologicamente em glomerulopatia do enxerto, multilaminação da membrana basal pericapilar tubular (mais de seis camadas à microscopia eletrônica) e fibrose arterial (além de fibrose intersticial/atrofia tubular [FI/ AT]), associada ao C4d (padrão semelhante à RA humoral) e anticorpos anti-HLA do doador ou antiantígenos endoteliais. Alguns autores consideram a rejeição crônica mediada por anticorpos um processo de acomodação parcial, por desordem da microcirculação, suficiente para impedir lise pelo complemento, porém insuficiente para prevenir ativação endotelial.

Nos casos de glomerulopatia crônica do transplante, sem depósitos de C4d, pesquisar problemas de fixação da amostra, lesão residual prévia, mediação por células T e causas não-imunológicas (microangiopatia trombótica e toxicidade a drogas).

\section{Alterações borderline}

O novo sistema Banff confirma esse diagnóstico quando há focos de tubulite $(\mathrm{t} 1, \mathrm{t} 2, \mathrm{t} 3)$ com infiltrado intersticial mínimo (i0 ou i1) ou tubulite discreta (t1) com inflamação intersticial (i2 ou i3).

\section{Rejeição mediada por células $\mathbf{T}$}

Recomenda-se a nomenclatura "rejeição mediada por células T" (aguda ou crônica), pois, apesar da presença 
de macrófagos, eosinófilos, células B e NK, o linfócito T é o componente efetor da resposta imunológica. O termo "rejeição crônica mediada por células T" pode ser utilizado em casos de arteriopatia obliterativa sem elastose ou componente humoral.

\section{Fibrose intersticial e atrofia tubular (FI/AT) sem evidências de etiologia específica}

A recomendação principal do Banff é a eliminação do termo "nefropatia crônica do enxerto", que foi introduzido em 1991, por ser termo descritivo, inespecífico.

Quando possível, além de Fl/AT, tentar definir a etiologia específica; por exemplo, hipertensão arterial, que é importante causa de insuficiência renal; a toxicidade por INC; e a infecção pelo poliomavírus, que, em fase de esclerose do enxerto, pode ser de difícil identificação; além de glomerulonefrite $(\mathrm{GN})$ recidivadas e diabetes mellitus.

É freqüente a presença de infiltrado linfomononuclear intersticial associado a áreas de fibrose nas mais diversas localizações e distribuições. No estudo feito por Mengel, observou-se que inflamação era freqüente tanto em enxertos estáveis quanto em disfuncionados; nestes, porém, a soma dos infiltrados relaciona-se com a deterioração da função. Em conclusão, não há infiltrado inflamatório inofensivo, a creatinina não é um marcador confiável e estudos prospectivos são necessários para melhor entendimento do papel das várias células no enxerto ${ }^{(36,37,45)}$. Com isso, o consenso do Banff recomenda o uso do escore "fibrose; inflamação" (F;i) para esse tipo de lesão.

Outras recomendações foram a utilização dos escores Banff para classificação de biópsias de doadores no tempo 0 e que a presença de lesões vasculares isoladas com escores $i$ e $t<1$, sem microangiopatia, em material adequado, deve ser apenas acompanhada. Também foi abordada a presença de depósitos $\mathrm{C} 4 \mathrm{~d}$ em capilares peritubulares em enxertos sem alterações histológicas, que é situação comum em transplantes $\mathrm{ABO}$ incompatíveis. Deve-se alertar o clínico de que o significado a longo prazo dessa situação não está estabelecido, recomendando-se acompanhamento do paciente.

Para finalizar, o uso de marcadores genômicos tem recebido atenção dos grupos envolvidos com transplante, com destaque para suas aplicações potenciais e sua provável introdução como um dos parâmetros para melhor acompanhamento dos pacientes.

\section{Referências}

1. AGUADO, J. M. et al. Encrusted pyelitis and cystitis by Corynebacterium urealyticum (CDC group D2): new and threatening complication following renal transplant. Transplantation, v. 56, n. 3, p. 617-22, 1993.

2. AUDARD, V. etal. Acute graft pyelonephritis: a potential cause of acute rejection in renal transplant. Transplantation, v. 80, n. 8, p. 1128-30, 2005.

3. BERTONI, E. et al. Limits of clinical signs and non-invasive techniques in detecting severe acute rejection. J Nephrol, v. 12, n. 2, p. 100-3, 1999.

4. BOREL, J. F. et al. The discovery and development of cyclosporine (Sandimmune). Transplant Proc, v. 23, n. 2, p. 1867-84, 1991.

5. BROOK, I. The role of anaerobic bacteria in perinephric and renal abscesses in children. Pediatrics Feb, v. 93, n. 2, p. 261-4, 1994.
6. CAMPOS, E. F. et al. Post-transplant anti-HLA class II antibodies as risk factor for late kidney allograft failure. Am J Transplant, v. 6, n. 10, p. 2316-20, 2006.

7. COLVIN, R. B.; NICKELEIT, V. Renal transplant pathology. In: JEANETTE, C. et al. Heptinstall's pathology of the kidney. $6^{\text {th }}$ ed. v. II. Philadelphia: Lippincott Williams \& Wilkins, 2007. p. 1448-9.

8. CORNELL, L. et al. Chronic allograft nephropathy. Curr Op Nephrol Hypertens, v. 14, n. 3, p. 229-34, 2005.

9. CosIO, F. G. et al. Predicting subsequent decline in kidney allograft function from early surveillance biopsies. Am J Transplant, v. 5, n. 10, p. 2464-74, 2005.

10. CosiO, F. G. et al. Transplant glomerulopathy. Am J Transplant, v. 8, n. 3, p. 492-6, 2008.

11. COTRAN, R. S.; KUMAR, V.; COLLINS, T. Diseases of immunity. In: COTRAN, R. S.; KUMAR, V.; COLLINS, 
T. Robbins pathologic basis of disease. $6^{\text {th }}$ ed. Philadelphia: W.B. Saunders, 1999. p. 206-11.

12. DAVID-NETO, E. et al. C4d-positive chronic rejection: a frequent entity with a poor outcome. Transplantation, v. 84, n. 11, p. 1391-8, 2007.

13. DRACHENBERG, C. D. et al. Polyomavirus disease in renal transplantation. Review of pathological findings and diagnostic methods. Hum Pathol, v. 36, n. 12, p. 1245-55, 2005.

14. DUNN, S. P. et al. Pyelonephritis following pediatric renal transplant: increased incidence with vesicoureteral reflux. J Pediatr Surg, v. 22, n. 12, p. 1095-9, 1987.

15. FURNESS, P. N. et al. International variation in histologic grading is large, and persistent feedback does not improve reproducibility. Am J Surg Pathol, v. 27, n. 6, p. 805-10, 2003.

16. GILLUM, D. M.; KELLEHER, S. P. Acute pyelonephritis as a cause of late transplant dysfunction. Am J Med, v. 78, n. 1, p. 156-8, 1985.

17. GIRAL, M. et al. Acute graft pyelonephritis and long-term kidney allograft outcome. Kidney Int, v. 61, n. 50, p. 1880-6, 2002.

18. GLADSTONE, A. A. et al. The role of early biopsy in cyclosporine-induced thrombotic microangiopathy. Pediatric Nephrol, v. 13, p. 564-6, 1999.

19. GLOOR, J. M. et al. Transplant glomerulopathy: subclinical incidence and association with alloantibody. Am J Transplant, v. 7, n. 9, p. 2124-32, 2007.

20. GRIMM, P. C. et al. Clinical rejection is distinguished from subclinical rejection by increased infiltration by a population of activated macrophages. J Am Soc Nephrol, v. 10, n. 8, p. 1582-9, 1999.

21. HAAS, M. et al. Acute renal allograft rejection with intimal arteritis: histologic predictors of response to therapy and graft survival. Kidney Int, v. 61, n. 4, p. 1516-26, 2002.

22. HAAS, M. etal. C4d staining in perioperative renal transplant biopsies. Transplant, v. 74, p. 711-7, 2002.

23. HALLORAN, P. F. et al. The significance of the anti-class I response. Clinical and pathologic features of renal transplants with anti-class I-like antibody. Transplant Int, v. 53, p. 550-3, 1992.

24. HELANTERÃ, I. et al. Timing and value of protocol biopsies in well-matched kidney transplant recipients: a clinical and histopathologic analysis. Transplant Int, v. 20, n. 11, p. 982-90, 2007.

25. HELLMAN, R. N. et al. Cryptococcal pyelonephritis and disseminated cryptococcosis in a renal transplant recipient. Arch Intern Med, v. 141, n. 1, p. 128-30, 1981.

26. HUMES, H. D. et al. Cyclosporine nephrotoxicity: a workshop to discuss mechanisms, diagnosis and treatment. Transplant Proc, v. 20, n. 3, p. 833-40, 1988.

27. ISONIEMI, H. et al. Histological chronic allograft damage index accurately predicts chronic renal allograft rejection. Transplantation, v. 58, n. 11, p. 1195-8, 1994.

28. KEE, T. Y. et al. Treatment of subclinical rejection diagnosed by protocol biopsy of kidney transplants. Transplantation, v. 82, n. 1, p. 36-42, 2006.
29. LIPTAK, P. et al. Primer: histopathology of calcineurininhibitor toxicity in renal allografts. Nat Clin Pract Nephrol, v. 2, n. 7, p. 398-404, 2006.

30. MacDONALD, F. et al. Banff criteria as predictors of outcome following renal acute allograft rejection. Nephrol Dial Transplant, v. 14, p. 1692-7, 1999.

31. MAO, Y. et al. Clinical significance of protocol biopsy at one month posttransplantation in deceased-donor renal transplantation. Transplant Immunol, v. 17, n. 3, p. 211-4, 2007.

32. MAUIYYEDI, S. et al. Acute humoral rejection in kidney transplantation: II. Morphology, immunopathology and pathologic classification. J Am Soc Nephrol, v. 13, n. 3, p. 779-87, 2002.

33. MAUIYYEDI, S. et al. Humoral rejection in kidney transplantation: new concepts in diagnosis and treatment. Curr Opin Nephrol Hypertens, v. 11, n. 6, p. 609-18, 2002.

34. MAUIYYEDI, S. et al. Chronic humoral rejection: identification of antibody-mediated chronic allograft rejection by $\mathrm{C} 4 \mathrm{~d}$ deposits in peritubular capillaries. $J$ Am Soc Nephrol, v. 12, p. 574-82, 2001.

35. MEEHAN, S. M. et al. De novo collapsing glomerulopathy in renal allografts. Transplantation, v. 65, n. 9, p. 11927, 1998.

36. MENGEL, M. et al. Infiltrates in protocol biopsies from renal allograft. Am J Transplant, v. 7, n. 2, p. 356-62, 2007.

37. MORESO, F. et al. Subclinical rejection associated with chronic allograft nephropathy in protocol biopsies as a risk factor for late graft loss. Am J Transplant, v. 6, n. 4, p. 747-52, 2006.

38. MUELLER, A. et al. Impact of the Banff '97 classification for histological diagnosis of rejection on clinical outcome and renal function parameters after kidney transplantation. Clin Transplant, v. 69, n. 6, p. 112327, 2000.

39. NANKIVELL, B. J. et al. Calcineurin inhibitor nephrotoxicity: longitudinal assessment by protocol histology. Transplantation, v. 78, n. 4, p. 557-65, 2004.

40. NANKIVELL, B. J. et al. Natural history, risk factors, and impact of subclinical rejection in kidney transplantation. Transplantation, v. 78, n. 2, p. 242-9, 2004.

41. NANKIVELL, B. J. Subclinical renal allograft rejection and protocol biopsies: quo vadis? Nat Clin Prat Nephrol, v. 4, n. 3, p. 134-5, 2008.

42. NANKIVELL, B. J. et al. The significance of subclinical rejection and the value of protocol biopsies. Am J Transplant, v. 6, n. 9, p. 2006-12, 2006.

43. NYBERG, G. et al. Morphologic findings in baseline kidney biopsies from living related donors. Transplant Proc, v. 24, p. 355, 1979.

44. OKAMOTO, M. et al. Ten-year protocol biopsy findings of renal allografts in the calcineurin inhibitor era. Clin Transplant, v. 20, n. 15, p. 16-9, 2006.

45. OZDEMIR, B. H. et al. Posttransplant tubulointerstitial nephritis: clinicopathological correlation. Transplant Proc, v. 38, n. 2, p.466-9, 2006.

46. PAJEK, B. A. et al. Follow-up of kidney graft recipients with cyclosporine-associated hemolytic-uremic syndrome and thrombotic microangiopathy. Transplant Proc, v. 37, n. 4, p. 1889-91, 2005. 
47. PEARSON, J. C. et al. Post-transplantation pyelonephritis: factors producing low patient and transplant morbidity. J Urol, v. 123, n. 2, p. 153-6, 1980.

48. PELLÉ, G. et al. Acute pyelonephritis represents a risk factor impairing long-term kidney graft function. Am J Transplant, v. 7, n. 4, p. 899-907, 2007.

49. PONTICELLI, C. Transplantation 2004: where do we stand today? Nephrol Dial Transplant, v. 19, n. 12, p. 2937-47, 2004.

50. RACUSEN, L. C. et al. The Banff 97 working classification of renal allograft pathology. Kidney Int, v. 55, n. 2, p. 713-23, 1999.

51. RACUSEN, L. C. et al. Banff 2003 Meeting Report: new diagnostic insights and standards. Am J Transplant, v. 4, n. 10, p. 1562-6, 2004.

52. RANDHAWA, P. S. et al. Biopsy of marginal donor kidneys: correlation of histologic findings with graft dysfunction. Transplantation, v. 69, n. 7, p. 1352-7, 2000.

53. ROBERTS, I. S. et al. Subclinical rejection and borderline changes in early protocol biopsy specimens after renal transplantation. Transplantation, v. 77, n. 8, p. 11948, 2004.

54. RUSH, D. N. et al. Histological findings in early routine biopsies of stable renal allograft recipients. Transplantation, v. 57, n. 2, p. 208-11, 1994.

55. SEEMAYER, C. A. et al. C4d staining of renal allograft biopsies: a comparative analysis of different staining techniques. Nephrol Dial Transplant, v. 22, n. 2, p. 568-76, 2007.

56. SERON, D. et al. Reliability of chronic allograft nephropathy diagnosis in sequential protocol biopsies. Kidney Int, v. 61, n. 2, p. 727-33, 2002.

57. SINGH, H. K. et al. Urine cytology findings of polyomavirus infections. In: AHSAN, N. etal. Polyomavirus and human diseases. New York: Springer, 2005. p. 201-12.

58. SIS, B. et al. Reproducibility studies on arteriolar hyalin thickening scoring in calcineurin inhibitor-treated renal allograft recipients. Am J Transplant, v. 6, n. 6, p. 1449-50, 2006.

59. SIS, B. et al. Transplant glomerulopathy, late antibodymediated rejection and the ABCD tetrad in kidney allograft biopsies for cause. Am J Transplant, v. 7, n. 7, p. 1743-52, 2007.

60. SOLEZ, K. et al. Report of the third Banff conference on allograft pathology (July 20-24, 1995) on classification and lesion scoring in renal allograft pathology. Transplant Proc, v. 28, n. 1, p. 441-4, 1996.

61. SOLEZ, K. et al. Banff 05 meeting report. Differential diagnosis of chronic allograft injury and elimination of chronic allograft nephropathy ("CAN"). Am J Transplant, v. 7, n. 3, p. 518-26, 2007.

62. SOLEZ, K. et al. Banff 07 Classification of Renal Allograft Pathology: updates and future directions. Am J Transplant, v. 8, n. 4, p. 753-60, 2008.

63. TERASAKI, P. I. et al. Predicting kidney graft failure by HLA antibodies: a prospective trial. Am J Transplant, v. 4, n. 3, p. 438-43, 2004.

64. THOMALLA, J. V. et al. Acute lobar nephronia of renal transplant allograft. Urology, v. 41, n. 3, p. 283-6, 1993.

65. WANG, H. J. et al. On the influence of sample size on the prognostic accuracy and reproducibility of renal transplant biopsy. Nephrol Dial Transplant, v. 13, n. 1, p. 165-72, 1998.

66. YANG, C. W. et al. Acute focal bacterial nephritis presented as acute failure and hepatic dysfunction in a renal transplant recipient. Am J Nephrol, v. 14, n. 1, p. 725, 1994.

67. YILMAZ, S. et al. Protocol core needle biopsy and histologic chronic allograft damage index (CADI) as surrogate end point for long-term graft survival in multicenter studies. J Am Soc Nephrol, v. 14, n. 3, p. 773-9, 2003. 